\title{
Therapeutic Application of Botulinum Toxin in Clinical Practice
}

\author{
Sandip Kumar Dash ${ }^{1, *}$ and M. Mohiuddin $\operatorname{Araf}^{2}$ \\ ${ }^{1}$ Consultant Neurologist and ${ }^{2}$ Consultant Physical Medicine, Apollo Hospital, Dhaka, Bangladesh
}

\begin{abstract}
Botulinum toxin, one of the most potent toxins known, is produced by Clostridium botulinum. It causes a temporary paralysis of muscles by inhibiting vesicular release of acetylcholine in neuromuscular junction and synaptic transmission at cholinergic nerve terminals and causes a temporary paralysis of muscles. Since the approval of botulinum toxin A by FDA for strabismus and blepharospasm in 1989 and botulinum toxin B for cervical dystonia in 2000, its therapeutic uses are expanding. To date, both the serotypes A and B have been used therapeutically. These include various dystonic movement disorders, lacrimal hypersecretion, hyperhydrosis, overactive bladder syndromes both neurogenic and idiopathic, prostatic hyperplasia, various gastrointestinal disorders, headache syndromes like migraine and various spastic disorders. Botulinum toxin does not correct the underlying pathology but only produces clinically symptomatic improvement. The duration of improvement and the percentage of improvement vary between different studies due to differences in doses used; different techniques used for injections and also the dilutions. Still more trials are required to explore newer indications of its use, to find out the exact effective doses, dilutions and techniques, so as to have a prolonged clinical improvement. Though it has a good safety profile, complications are related to chemodenervation of adjacent muscles and injection techniques. This article provides an update on different uses of botulinum toxin in medicine.
\end{abstract}

Key Words: Botulinum toxin, botox in clinical practice, botulinum toxin in medicine.

\section{INTRODUCTION}

Botulinum toxin, one of the most potent toxins known, is produced by clostridium botulinum. It is associated with lethal outbreaks of food poisoning. A very small amount of toxins produces a descending paralysis with prominent bulbar symptoms and at times autonomic symptoms. It exerts its toxic effect by inhibiting synaptic transmission at cholinergic nerve terminals by preventing exocytosis of acetylcholine. Toxic effects occur mainly at the neuromuscular junction, but ganglionic nerve terminals can be affected [1].

Strains of clostridium botulinum produce seven antigenically distinct neurotoxins as serotypes $A$ to $G$, out of which the most stable and most potent exotoxin is botulinum toxin A (Botox-A). All seven serotypes contain a unique zinc dependant endo - peptidase the light chain, which is bound to a heavy chain and joined by a disulfide bond, in complex with hem agglutinin \& nontoxic-non hem - agglutinin proteins. Different preparations have different total weights of these complexes. The total weight complex may be a factor, determining diffusion of the toxin from the site where it is injected [2]. The toxin inhibits the release of acetylcholine at terminals of cholinergic neurons at the neuromuscular junction. With the propagation of action potential there is an activation of calcium channels, which in turn cause Synaptosomal Associated Protein Receptor (SNARE) proteins to aggregate to form complexes. This causes the fusion of vesicle containing acetylcholine with the synaptic membrane and

*Address correspondence to this author at the Consultant Neurologist, Apollo Hospital, Dhaka, Bangladesh; Tel: +8801713047523;

E-mail: drskdash@yahoo.co.in acetylcholine is released in to neuromuscular junction. The toxin inhibits the aggregation and complex formation of SNARE proteins. The SNARE complex consists of synaptosomal associated protein (SNAP25), Synaptobrevin or vesicle Associated Membrane Protein (V Amp) and Syntaxin [3]. They bind to the presynaptic membrane by heavy chain and is internalized to the cytosol of the membrane, where the light chain is catalytic and translocated to the external surface of the synaptic vesicle, deactivates the SNARE proteins that are needed for ducking and fusion of the synaptic vesicle with the terminal membrane [4]. Botulinum toxin B, D, F \& $\mathrm{G}$ cleave specifically at single but different peptide bonds Vamp / synaptobrevin, a membrane protein of synaptic vesicle. Botulinum toxin A, C, E cleaves SNAP 25 at different sites, where as Botulinum toxin $\mathrm{C}$ also cleaves Syntaxin [5]. They all interfere with neuromuscular transmission by blocking the release of acetylcholine and cause muscular weakness. Denervation of neuromuscular junction does not cause permanent damage to nerve terminals and is reversible and the functions can be recovered by axonal sprouting and formation of new synaptic contacts, which usually takes two to three months [6]. The mechanism of recovery is not known. A reduction in acetylcholine esterase levels lead to receptor sensitivity and there is up regulation of extrajunctional acetylcholine receptors along with increased lysosomal and endolytic activity, which may contribute to recovery [7]. In 1989, FDA approved botulinum toxin A (Botox) as a therapeutic agent in patients with strabismus, blepharospasm and other facial nerve disorders [8]. In 2000, FDA approved botulinum toxin A and botulinum toxin B (Myobloc) as the treatment for cervical dystonia and Botox cosmetics for the treatment of glabellar lines [6]. 
Botulinum toxin has to be injected to the affected muscles or glands. The doses vary according to the condition and also the size of affected muscles; the large muscles require high doses. Affected muscles can be identified by muscular hypertrophy, stiffness and visible abnormal activity. EMG is useful to identify the affected muscle. In addition, an application in pain management has been indicated by the ability of botulinum toxin to inhibit neuropeptide release from nociceptors, thereby blocking central and peripheral pain sensitization process [9].

The effect of botulinum toxin lasts only for about 3 months after which the patient will need further injection. Patients will experience relief of symptoms after each injection, followed by gradual resistance to further injection due to the development of neutralizing or blocking antibodies [10]. The mechanism of this resistance is unknown. However, immuno resistant patients account for fewer than half of patients with poor out comes, which are likely due to technical aspects of injection, including selection of muscles injected, dose, dose limiting side effects like localized weakness or incorrect diagnosis. Advances in the purification of botulinum toxin have further reduced the risk of an immunological side effect. This resistance can be detected by mouse protection assay or clinically by unilateral brow injection which fails to produce paralysis of corrugator or procerus muscle [6]. The presence of blocking antibodies implies that the patient will not respond to the same serotype, but may respond to an alternate type; however there may be immuno resistance due to cross reactivity.

The development of resistance can be minimized by giving the lowest effective dose \& long intervals between the injections. In the current Botox preparation the risk of development of blocking antibodies is nil in comparison to $9.5 \%$ of risk in original botulinum toxin A and the risk of antibody formation is low after current botulinum toxin type A treatment is related to the lower protein load [11]. Serotype B is the focus of several studies in patients resistant to conventional Botox A (botulinum toxin A). One indication in which resistance to Botox A is described is cervical dystonia, where treatment with Botox B is effective. But those responding to botulinum toxin A have a marginally longer duration of effect in comparison to botulinum toxin B [12].

Botox $\mathrm{F}$ is beneficial in patients who are resistant to Botox A. Better results are possible with higher doses of botulinum toxin $\mathrm{F}$ but the duration of benefit is still shorter than with botulinum toxin A, seemingly due to a shorter duration of neuromuscular junction blockade [13].

\section{THERAPEUTIC APPLICATIONS}

Since the introduction of botulinum toxin in clinical practice, its use has been expanding over the years. Botulinum toxin injection results in relief of symptoms, but it does not correct the underlying pathology. Botulinum toxin injection is found to be effective in various disorders of neurological, ophthalmic, gastrointestinal, urological, headache and dermatological conditions.

\section{Strabismus}

This is characterized by lack of ocular parallelism and is associated with over contractile state of ocular muscles. In- jection of botulinum toxin (Botox) to the over contractile muscle causes weakness of the over active muscle and corrects strabismus. It reduces ocular deviation by $50-80 \%$ [14], making it an alternative option to surgery. Complications like transient ptosis, and sub conjuctival hemorrhage may occur.

\section{Elevated Intraocular Pressure from Restrictive Myopathy}

Patients of thyroid ophthalmopathy having restrictive myopathy may have elevated intraocular pressure in up gaze, which is difficult to manage medically and may require orbital decompression. In a small study of 8 patients it is seen that botulinum toxin injection to inferior rectus muscle causes reduction in intraocular pressure [15] which may be due to a decreased tone in extra ocular muscle and possibly due to a reduced orbital volume.

\section{Chronic Dry Eyes}

Injection of botulinum toxin to medial portion of the orbicularis oris muscle of lower eye lid or both lids has been found to be effective in decreasing lacrimal drainage, suggesting a new way to treat dry eye conditions. It is reported in a study that there is a subjective improvement in dry eye symptoms in $70 \%$ of patients [16].

\section{Post Peripheral Facial Nerve Synkinesis}

After facial nerve paralysis axonal regeneration leads to hyperactivity of the previously paralyzed muscles. Abnormal axonal branching leads to synkinetic movements characterized by involuntary contraction of muscles innervated by other branches. It is seen that a single injection of botulinum toxin is highly effective in reducing the synkinetic movements for 3-9 months [17, 18].

\section{Hemi Facial Spasm}

Hemifacial spasm is a dystonic movement of lower facial muscles. After local injection of botulinum toxin injection (Botox); it is seen that about $95 \%$ of patients had marked to moderate improvement [19].

\section{Cervical Dystonia}

This is an involuntary posture or movement of head and neck.

Spasmodic torticollis is the most common abnormal head posture. Many patients also demonstrate complex head movements. Both botulinum toxin type A\&B are approved by F D A for the treatment of cervical dystonia. The toxin is injected directly into the muscles, most commonly the ipsilateral splenium capitis, sceleneus, trapizius, levator scapulae, deep paraspinal muscle, and contra-lateral sternocleidomastoid muscle. The long term safety and efficacy of botulinum toxin A in cervical dystonia is approximately $60 \%$ in patients treated over more than 10 years [20]. It is seen that chronic treatment with botulinum toxin in patients with cervical dystonia is not associated with any decline in benefit. The efficacy may improve slightly with repeated treatment [21]. The side effects like dysphagia, dysarthria, weakness and dry mouth are less in cases of botulinum toxin type A in comparison to botulinum toxin B [12]. 


\section{Oromandibular Dystonia}

In this condition there is involuntary opening and closing of jaw. Injections are given into masseter, temporalis and internal pterygoids for jaw closing, and digastric's and external pterygoids for jaw opening. Symptoms are reduced in 73\% of patients [22]. Except for transient focal weakness, there are very few complications or systemic effects attributed to the injection. Early treatment seems to improve the success rate.

\section{Laryngeal Dystonia}

In this type of dystonia there is either a strangled voice or a breathy whisper voice. Botulinum toxins in low doses in to laryngeal muscles produce improvement in speech and are now the treatment of choice in this disorder [23]. Treatment with Botox results in normal or near normal voice in patients with adductor type dystonia and have considerable benefit in abductor type i.e. breathy, whispery voice [24]. A unilateral or bilateral EMG guided approach or indirect laryngoscopy without EMG has been used to inject the toxin to thyroarytenoid muscle. Adverse effects like hypophonia, hoarseness, dysphasia and stridor may occur but are temporary [6]. However, there is an improvement in the quality of life. In adults with disabling stuttering, botulinum toxin injection produces less consistent results.

\section{Writer's Cramp}

Injection of Botulinum toxin has been found to provide relief for writer's cramp. Pain is generally improved more than motor function. Botulinum toxin type A injections are effective in relieving symptoms in selected cases of writer's cramp, particularly in those with pronation / flexion pattern of dystonia. The writing speed improves both subjectively \& objectively [25]. There is some weakness associated with improvement. The relief is only symptomatic and it does not reverse the associated dysfunction of primary motor and premotor cortex [26]. It is seen that $36 \%$ of patients continued to have relief when followed up for a mean period of 12 months [27].

\section{Tics}

Botulinum toxin also gives satisfactory results in tics, myoclonic jerks, and stuttering, [28], including motor tics associated with Tourret syndrome [29].

\section{Spasticity}

Botulinum toxin has been found to be effective in various spastic disorders. It has been found to relieve spasticity in cerebral palsy, strokes, multiple sclerosis, and traumatic spinal cord injury. Injections are said to relieve the muscle spasm, allowing the caregiver to wash, dress the patient \& also relieve pain. It is seen that local injection of botulinum toxin can relieve disability of wrist and fingers after a stroke in $62 \%$ of subjects and the benefit lasted for 12 weeks [30]. Injection of botulinum toxin to patients of multiple sclerosis having spasticity of hip adductors also relieves muscle spasm and functional improvement. In Parkinsonism local injection of botulinum toxin also improves spasticity and rigidity. There is a clear temporal relationship between Botulinum toxins A injection in to calf muscles of parkinsonism patients and improvement in freezing of gait. In a study it is seen that $40 \%$ reported marked improvement in freezing of gait and the mean duration of improvement lasted for 6 weeks [31]. Botulinum toxin injection has also been found to be safe and effective in the treatment of spastic toes [32]. Use of intramuscular botulinum toxin type $\mathrm{A}$ as an adjunct to physiotherapy and orthoses helps to reduce spasticity and improve functional mobility in children with spastic diplegia or hemiplegia in cerebral palsy [33], there by improvement of gait occurs in children with cerebral palsy.

\section{Tremor}

Benign essential tremor is the most common cause of clinically symptomatic tremor. It is due to oscillatory contraction of reciprocally innervated agonist and antagonist muscles. Botulinum toxin has been used for treatment of essential tremor with significant improvement in postural tremor of hand [34]. Treatment with botulinum toxin is worth considering in these conditions, but the main disadvantage is a dose dependant hand weakness.

\section{Focal Hyperhydrosis}

In this condition there is excessive sweating of the palms, feet and axilla. Botulinum toxin injection considerably reduces the secretion of sweat. In an open study of higher dose of botulinum toxin A in axillary hyperhydrosis [35], it was seen that intracutaneous high dose of botulinum toxin is capable of prolonging the anhydrotic effect in most patients. The duration of effect lasted for more than 19 months. The relapse rate was reduced after 12 months and there was no evidence of induction of neutralizing antibodies, confirming the safety of high dose of treatment. In randomized study [36], botulinum toxin B is also found to be effective in axillary hyperhydrosis, but the duration of effect was $2-8$ months with a mean of 5 months. In a randomized study of 24 patients with severe palmar hyperhydrosis, it was seen that there was decreased sweating in patients with primary hyperhydrosis for at least 2 months in all the patients, and 6 months in most patients [37]. Botulinum toxin has turned out to be a simple and highly effective treatment option for pathological lacrimation and also in gustatory sweating [38]. Sialorrhea associated with amyotrophic lateral sclerosis, has been successfully treated with botulinum toxin in selected patients [39]. It is seen that anatomically guided injection of botulinum toxin B into the parotid and submandibular glands appears to improve sialorrhea effectively without compromising dysphagia in patients with Parkinson's disease [40].

\section{Urinary Bladder Dysfunction}

Injection of botulinum toxin is primarily used in detrusor sphincter dysynergia, frequently seen in traumatic spinal cord injury or in multiple sclerosis. In this condition there is insufficient relaxation and uncoordinated contraction of vesicular sphincter during micturition, causing complications like residual urine and ureteric reflux ultimately leading to renal damage. The rational for using botulinum toxin is to weaken both the external and internal sphincter. Success rate of 58-88\% has been reported when injections are given under urethroscopy or by EMG guidance [41]. Botulinum toxin has been found to be effective in voiding dysfunction from prostatitis [42]. Studies in patients with obstructive prostate 
either hyper plastic or not, have used botulinum toxin with varying doses, dilutions and techniques and found improvement in prostatic volume, urinary flow rate and in residual urine and improvement in the quality of life [43, 44]. In addition some patients were able to void spontaneously. Injection of botulinum toxin to the external urethral sphincter seems to have a beneficial effect on chronic prostatic pain, presumably by reducing the hyper tonicity and hyperactivity of the external urethral sphincter [45]. Botulinum toxin has been found to be an effective therapy in overactive bladder both neurogenic and in idiopathic detrussor over activity. In a study of 24 patients [46] of neurogenic and idiopathic detrussor over activity, it is seen that improvement in urgency occurred first followed by incontinence and the improvement persisted up to 4 weeks. Botulinum toxin injection is effective in patients having spinal cord lesion with neurogenic detrussor over activity, even in patients with low bladder compliance. The patient may require repeat injection after 16 weeks to remain continent [47]. Botulinum toxin has been found to be effective in painful bladder, which is characterized by bladder pain that increases with bladder filling accompanied by increased day time frequency, nocturea and urgency in the absence of urinary tract infection or obvious underlying pathology. Three pilot studies using botulinum toxin in this condition with varying doses, and techniques, reported that the response rate of $20-85 \%$ and the duration of effect lasting between 1-8 months [48-50]. In a prospective study of effect of botulinum toxin A in painful bladder syndrome, at 1 year follow up, it was seen that the beneficial effect lasted at 3 months in $86 \%$ and $30 \%$ at 5 months. There was a significant decrease in pain, accompanied by increase in maximum cystometric capacity and in day time and night time urinary frequency, but after 1 year pain had recurred in all, requiring repeat injection [51]. However, this requires confirmation by a randomized placebo controlled study.

\section{Gastrointestinal Disorders}

Botulinum toxin injection appears to be safe and effective in dysphagia due to achalasia, esophageal spasm, spasm of sphincter of oddi, anal fissure and anismus. It may be a therapeutic option in elderly patients with achalasia unsuitable for surgery or pneumatic dilatation [52]. This treatment is most effective in elderly as symptomatic relief can last up to one to two years with a single injection [53].In a study of patients with diabetic gastro paresis, botulinum toxin injection to the pylorus was found to relieve symptoms of gastro paresis [54]. In a review of the use of botulinum toxin in a large number of patients with gastro paresis it was found that $43 \%$ had a response to botulinum toxin treatment that lasted approximately up to 5 months, male gender was associated with a response and presence of vomiting as a major symptom predicted no response to botulinum toxin injection [55]. In a meta analysis of three randomized control trials, it is seen that botulinum toxin is as effective as glyceryl trinitrate for the management of chronic anal fissure and is associated with a lower complication rate. Botulinum toxin can be recommended as first line therapy for chemical sphincterotomy in patients of chronic anal fissure [56]. However, this requires a major and multicenter randomized trial to confirm this. Injection of botulinum toxin has been found to be an effective treatment in chronic anal fissure. When compared with topical nitroglycerin, botulinum toxin is a more effec- tive option, which acts as an alternative to surgery in patients with chronic anal fissure [57]. Basing on the concept of gastric injection of botulinum toxin, it may reduce the gastric emptying and body weight. In a study [58] it was seen that intra gastric injection is associated with weight loss and slowing of gastric emptying. However, it needs to be studied in a large number of cases to find out the doses required and the effectiveness of this form of treatment in cases of obesity.

\section{Chronic Low Back Pain}

Injection of botulinum toxin into para - vertebral muscles in patients of chronic low back pain, causes relief of pain and improvement of function in 3 weeks and 8 weeks after treatment [59].

Botulinum toxin injection to frontotemporlis muscle reduces the EMG artifacts and helps in localizing the seizure focus and in epilepsy surgery [60].

Botulinum toxin has been found to be useful in many dermatological conditions like treatment for improving glabellar frown lines. Repeated injections are necessary to maintain a long term effect [61].

\section{Headache}

Botulinum toxin has been found to be effective in tension headache and is thought to be due to its muscle relaxation /paralytic properties. The toxin is also capable of blocking the release of neurotransmitter, including substances $\mathrm{P}$, from sensory nerve endings or nerve fibers innervating blood vessels near injection site [62]. Botulinum toxin injection is also useful in management of refractory headache. Various studies have shown that local injection of botulinum toxin is helpful and effective as a prophylactic treatment in migraine $[63,64]$. It decreases the headache frequency, headache intensity, and headache related disability in episodic and chronic migraine patients. In a pilot study [65] to find out the possible predictors of response to botulinum toxin $\mathrm{A}$ in the prophylaxis of chronic daily headache. it is seen that chronic migraine patients respond better than chronic tension type of headache, unilateral headache, presence of scalp allodynia, pericranial muscle tenderness appear to be predictors of response to botulinum toxin $\mathrm{A}$ in chronic migraine, where as pericranial muscle tenderness may be a predictor of response in chronic type of tension type of headache. In a study [66] comparing the effectiveness of botulinum toxin versus divalproex sodium as a prophylactic management in cases of migraine, it was found that both reduced the headache frequency and the disability associated with migraine. However, botulinum toxin was better tolerated and associated with fewer side effects in comparison to divalproex sodium. Duration of illness emerged as a predictor of treatment response. It is seen that subjects with migraine with the duration of more than 30 years were significantly less likely to respond to treatment with botulinum toxin-A [67]. In a study of 8 patients with trigeminal neuralgia, it has been found that injection of botulinum toxin in to the region of zygomatic arch is effective [68].

\section{CONCLUSION}

Botulinum toxin causes temporary paralysis of muscles lasting for 3-4 months, by preventing release of acetylcho- 
line at cholinergic junctions. It has an excellent safety and tolerability profile. The development of new botulinum toxin formulations has reduced the risk of neutralizing antibody formation. It is now widely used in various neurological, ophthalmological, urological, dermatological and gastrointestinal disorders, where it gives very good results. In various spastic disorders, by reducing the spasticity it helps in mobility and in physiotherapy. In cerebral palsy as an adjunct to physiotherapy and orthosis, improves the functional mobility and being able to delay or even avoid surgery until motion patterns become established. Current studies are directed towards newer clinical applications, exact dose of the injection and for better results without having any adverse events. Toxin type $\mathrm{F}$ is effective but have a shorter duration of effects. These may be useful in patients who develop antibodies to type A and B. So more studies are required to explore the effectiveness of other serotypes.

\section{ACKNOWLEDGEMENTS}

I am thankful to Dr. (Mrs.) Sujata Dash, M.Phil, Ph.D. and Sampad Dash for proof reading of this article.

\section{ABBREVIATIONS}

$$
\begin{aligned}
& \text { F.D.A }=\text { Food Drug Administration } \\
& \text { SNAP }=\text { Synaptosomal Associated Protein } \\
& \text { SNARE }=\text { Synaptosomal Associated Protein Receptor } \\
& \text { BOTOX }=\text { Botulinum toxin } \\
& \text { EMG }=\text { Electromyography }
\end{aligned}
$$

\section{REFERENCES}

[1] Janovic J, Brin MF. Therapeutic uses of botulinum toxin. New Eng J Med 1991; 324: 1186-94.

[2] Muthane UB, Panikar JN. Botulinum toxins: Pharmacology and its current therapeutic evidence for use. Neurol India 2003; 51: 45560 .

[3] Bali J, Thakur R. Poison as cure: A clinical review of Botulinum toxin as an invaluable drug. J Vnom Anim Toxin Incl Trop Dis 2005; 11: 412-21.

[4] Fishman P. Clinical uses of botulinum toxin. Adv Stud Med 2005; 5(4): 176-82.

[5] Rossetto O, Seveso M, Caccin P, Shiavo G, Montecucco C. Tetanus and botulinum neurotoxins: Turning bad guys in to good by research. Toxicon 2001; 39(1): 27-41.

[6] Janovic J. Botulinum toxin in clinical practice. J Neurol Neurosurg Psychiatr 2004; 75: 951-7.

[7] Tagerud S, Libelius R, Thesleff S. Effects of botulinum toxin induced muscle paralysis on endocytosis and lysosomal enzyme activities in mouse skeletal muscle. Pflugers Arch 1986; 407: 275-8. Cross ref.

[8] National Institutes of Health consensus Development conference statement, November 12-14. 1990: Clinical use of botulinum toxin. Arch Neurol 1991; 48: 1294-8.

[9] Dolly JO, Aoki KR. The structure and mode of action of different botulinum toxins. Eur J Neurol 2006; 13(Suppl 4): 1-9.

[10] Hanna PA, Jancovic A, Vincent A. Comparison of mouse bio assay and immunoprecipitation assay for botulinum toxin antibodies. $\mathbf{J}$ Neurol Neurosurg Psychiatr 1999; 66: 612-16.

[11] Jancovic J, Vuong KD, Ashan J. Comparison of efficiency and immunogenicity of original versus current botulinum toxin in cervical dystonia. Neurology 2003; 60: 1186-8.

[12] Caomella CL, Jancovic J, Shannon KM, et al. Comparison of botulinum toxin serotype A and B for the treatment of cervical dystonia. Neurology 2005; 65: 1423-9.

[13] Houser MK, Sheean GL, Lees AJ. Further studies using higher doses of botulinum toxin type $\mathrm{F}$ for torticollis resistant to botu- linum toxin type A. J Neurol Neurosurg Psychiatr 1998; 64: 57780.

[14] Carruthers JDA, Kenedy RA, Bagaric D. Botulinum toxin versus adjustable suture surgery in the treatment of horizontal mis alignment in adult patients lacking fusion. Arch Ophthalmol 1990; 108: $1432-8$.

[15] Kikkawa DO, Cruz RC, Christian WK, et al. Botulinum A toxin injection for restrictive myopathy of thyroid related orbitopathy: effect of intra ocular pressure. Am J Opthalmol 2003; 135: 427-31.

[16] Sahin S, Chen E, Kaugesaar T, et al. Effect of botulinum toxin injection on lacrimal drainage. Am J Ophthalmol 2000; 129: 481-6.

[17] Finn JC. Botulinum toxin type A: fine tuning treatment of facial nerve injury. J Drugs Dermatol 2004; 3: 133-4.

[18] Chua CN, Quhil F, Jones E, et al. Treatment of aberrant facial nerve regeneration with botulinum toxin A. Orbit 2004; 23: 213-8.

[19] Wang A, Jancovic J. Hemifacial spasm clinical co-relates and treatment. Muscle Nerve 1998; 21: 740-7.

[20] Haussermann P, Marczoch S, Klinger C, et al. Long term follow-up of cervical dystonia patients treated with botulinum toxin A. Mov Disord 2004; 19: 303-8.

[21] Jancovic J, Kenneth S, Schwartz PA. Longitudinal experience with botulinum toxin injections for treatment of blepharospasm and cervical dystonia. Neurology 1993; 43: 834-6.

[22] Jancovic J, Schwartz K, Donovan DT. Botulinum toxin treatment of cervical dystonia, spasmodic dysphonia, other focal dystonias and hemifacialspasm. J Neurol Neurosurg Psychiatry 1990; 53: 633-9.

[23] Watt SC, Nye C, Whurr R. Botulinum toxin for treating spasmodic dysphonia (Laryngeal dystonia): a systemic chrochane review. Clin Rehabil 2006; 20: 112-22.

[24] Biltzer A, Brin MF. Laryngeal dystonia, a series with botulinum toxin therapy. Ann Otol Rhinol Laryngol 1991; 100: 85-9.

[25] Djebbari R, Montcel ST, Sangla S, Vidal JS, et al. Factors predicting improvement in motor disability in writer's cramp treated with botulinum toxin. J Neurol Neurosurg Psychiatry 2004; 75: 1688-91.

[26] Ceballos Baumanno AO, Sheean G, Passingham RE, Marsden CD, Brooks DJ. Botulinum toxin does not reverse the cortical dysfunctions associated with writers cramp, A PET study. Brain 1997; 120: 571-82.

[27] Turjanki N, Pirtosek Z, Quirk J, et al. Botulinum toxin in the treatment of writers cramp. Clin Neuropharmacol 1996; 19: 314-20.

[28] Cordivari C, Misra VP, Catania S, Lees AJ. New therapeutic indications for botulinum toxins. Move Disorder 2004; 19(Suppl.8): S157-61

[29] Singer HS. The treatment of tics. Curr Neurol Neurosci Rep 2001; 1(2): 195-202.

[30] Brashear A, Gordon MF, Elovic E, et al. Intramuscular injection of botulinum toxin for the treatment of wrist \& finger spasticity after a stroke. N Eng J Med 2002; 347: 395-400.

[31] Giladi N, Gurevich T, Shabtai H, Paleacu D, Simon ES. Effect of botulinum toxin in calf muscles on freezing of gait in parkinsonism: a pilot study. J Neurol 2001; 248: 572-6.

[32] Suputtitada A. Local botulinum toxin type A injecting in the treatment of Spasticity. AM J Phys Med Rehabil 2002; 81(10): 770-5.

[33] Ubhi T, Bhakta BB, Ives HL, Allgar V, Roussounis SH. Randomised double blind placebo controlled trial of the effect of botulinum toxin or walking in cerebral palsy. Arch Dis Child 2000; 83(6): 481-7.

[34] Brin MF, Lyons KE, Doucette J, et al. A Randomized, double masked, controlled trial of botulinum toxin A, in essential tremor. Neurology 2001; 56: 1523-8.

[35] Wollina U, Karamfilo VT, Konard H. Higher dose botulinum toxin, A therapy for axillary hyperhydrosis markedly prolongs relapse free interval. AM Acad Dermatol 2002; 46(4): 536-40.

[36] Baumann L, Slezinger A, Helem M, et al. Pilot study of the safety and efficacy of myoblock (botulinum toxin B) for the treatment of axillary hyperhydrosis. Int J Dermatol 2005; 44(5): 418-24.

[37] Saadia D, Voustianiouk A, Wang AK, et al. Botulinum toxin type A in palmar hyperhydrosis, randomized, single double blind two dose study. Neurology 2001; 57: 2095-9.

[38] Toyka KV, Reiners K, Naumann M, Zelliner M. Botulinum toxin in the treatment of gustatory sweating. Annal Neurol 1997; 42: 973-5.

[39] Giess R, Naumann M, Werner E, et al. Injections of botulinum toxin $\mathrm{A}$ in to the salivary glands improves sialorrhea in amyotro- 
phic lateral sclerosis. J Neurol Neurosurg Psychiatry 2000; 69: 1213.

[40] Ondo WG, Hunter C, Moore W. A double blind placebo controlled trial of botulinum toxin B for sialorrhea in Parkinson's disease. Neurology 2004; 62(1): 37-40.

[41] Schrch B, Hauri D, Rodic B, et al. Botulinum toxin as a treatment of detrusor sphincter dysynergia a prospective study in 24 spinal cord injury. J Urol 1996; 155: 1023-9.

[42] Maria G, Destito A, Lacquanti S, et al. Relief by botulinum toxin of voiding dysfunction due to prostatitis. Lancet 1998; 352: 625.

[43] Chuang YC, Chiang PH, Huang CC, Yoshimura N, Chancellor MB. Botulinum toxin type A improves benign prostatic hyper plasia symptoms in patients with small prostates. Urology 2005; 64(4): 775-9.

[44] Chuang YC, Ciang PH, Youshimura N, De Miquel F, Chancellor MB. Sustained beneficial effects of intra-prostatic botulinum toxin type A on lower urinary tract symptoms and quality of life in men with benign prostatic hyperplasia. B J U Int 2006; 98(5): 1033-4.

[45] Leippold T, Reitz A, Schurch B. Botulinum toxin a new therapy option for voiding disorder, current state of the art. Eur Urol 2003; 44(2): 165-74.

[46] Kalsi V, Apostdidis A, Gonzales G, Elneil S, Dasgupta P, Fowler CJ. Early effects on the overactive bladder symptoms following botulinum neurotoxin type injections for detrussor over activity. Eur Urol 2008; 53(6): 1245-53.

[47] Klaphajone J, Kitisomprayoonkul W, Sriplakit S. Botulinum toxin type A injections for treating Neurogenic detrussor over activity combined with low compliance bladder in patients with spinal cord lesion. Arch Phys Med Rehabil 2005; 86(11): 2114-8.

[48] Smith CP, Radzisazewski P, Borkowski A, et al. Botulinum toxin A has antinociceptive effects in treating interstitial cystitis. Urology 2004; 64(5): 871-5.

[49] Kuo H. Preliminary results of sub urothelial injection of botulinum toxin $\mathrm{A}$ in the treatment of chronic interstitial cystitis. Urology Int 2005; 75: 170-4

[50] Giannantoni A, Costantine E, Di Stasi SM, et al. Botulinum toxin A intravesicle injection in the treatment of painful bladder syndrome: a pilot study. Eur Urol 2006; 49(4): 704-9.

[51] Giannantoni A, Porena M, Costantini E, Zuchhi A, Mearini L, Mearini E. Botulinum toxin A intravesicle injection in patients with painful bladder syndrome: 1 year follow up. J Uro 2008; 179; 1031-4.

[52] Luca D, Edda B, Dario M, et al. Botulinum toxin treatment of esophageal achalasia in the old and oldest: A 1 year follow-up study. Drugs Aging 2005; 22: 779-83.

[53] Richter JE. Modern management of achalasia. Curr Treat option Gastroenterol 2005; 8(4): 275-83.
[54] Lacy BE, Crowell MD, Schetter-Duncan A, Mathis C, Pasricha PJ. The treatment of diabetic gastro paresis with botulinum toxin injection of the pylorus. Diabet Care 2004; 27(10): 2341-7.

[55] Bromer MQ, Friedenberg F, Miller LS, et al. Endoscopic pyloric injection of botulinum toxin A for the treatment of refractory gastroparesis. Gastrointest Endosc 2005; 61(7): 833-9.

[56] Sajid MS, Vijaynagar B, Desai M, Cheek E, Baig MK. Botulinum toxin vs. glyceryl trinitrate for the medical management of chronic anal fissure: a meta analysis. Colorectal Dis 2008; 10(6): S41-6.

[57] Brisinda G, Cadeddu F, Brandara F, Marniga G, Maria G. Randomized clinical trial comparing botulinum toxin injection with 0.2 percent nitroglycerin ointment for chronic anal fissure. $\mathrm{Br} \mathrm{J}$ Surg 2007; 94(2): 162-7.

[58] Topazian M, Camilleri M, Levy D, et al. Endoscopic ultrasound guided gastric botulinum toxin injection in obese subjects: a pilot study. Obes Surg 2008; 18(4): 401-7.

[59] Foster L, Clapp L, Erickson M, Jabri B. Botulinum toxin A and chronic low back pain a randomized, double blind study. Neurology 2001; 56: 1290-93.

[60] Eisenchenk S, Gilmore RL, Uthaman B, et al. Botulinum toxin induced paralysis of fronto temporalis muscles improves seizure focus localization. Neurology 2002; 58: 246-9.

[61] Framton JE, Easthope SE. Botulinum toxin A (BOTOX): A review of its use in the treatment of glabellar frown lines. Am J Clin Dermatolo 2003; 4: 709-25.

[62] Aoki KR. Evidence for anti nociceptive activity of botulinum toxin type A in pain management. Headache 2003; 43: S9-S15.

[63] Chilson CN, Brown SJ. Role of botulinum toxin type A in the prophylactic treatment of migraine headache. Ann pharmacother 2005; 39(12): 2081-5.

[64] Dodick DW, Mauskop A, Elkind AH, et al. Botulinum toxin type A for the prophylaxis of chronic daily headache, sub group analysis of patients not receiving other prophylactic medication, a randomized double blind placebo controlled study. Headache 2005; 45: 315-24.

[65] Mathew NT, Kailsam J, Meadors L. Predictors of response to botulinum toxin types A (Bo NT A) in chronic daily headache. Headache 2008; 48: 194-200.

[66] Blumenfeld AM, Schim JD, Chippendale TJ. Botulinum toxin type A and divalproex sodium for prophylactic treatment of episodic or chronic migraine. Headache 2008; 48(2): 210-20.

[67] Eross EJ, Gladstone JP, Lewis S, Roger SR, Dodick DW. Duration of migraine is a predictor for response to botulinum toxin type A. Headache 2005; 45(4): 308-14.

[68] Turk V, Ilhan S, Alp R, Sur H. Botulinum toxin and intractable Trigeminal Neuralgia. Clin Neuro pharmacol 2005; 28(4): 161-2.

(C) Dash and Araf; Licensee Bentham Open.

This is an open access article licensed under the terms of the Creative Commons Attribution Non-Commercial License (http: //creativecommons.org/licenses/ by-nc/3.0/) which permits unrestricted, non-commercial use, distribution and reproduction in any medium, provided the work is properly cited. 